\title{
Excitatory GABA Action Is Essential for Morphological Maturation of Cortical Neurons In Vivo
}

\author{
Laura Cancedda, ${ }^{\star}$ Hubert Fiumelli, ${ }^{\star}$ Karen Chen, and Mu-ming Poo \\ Division of Neurobiology, Department of Molecular and Cell Biology, Helen Wills Neuroscience Institute, University of California at Berkeley, Berkeley, \\ California 94720-3200
}

\begin{abstract}
GABA exerts excitatory actions on embryonic and neonatal cortical neurons, but the in vivo function of this GABA excitation is essentially unknown. Using in utero electroporation, we eliminated the excitatory action of GABA in a subpopulation of rat ventricular progenitors and cortical neurons derived from these progenitors by premature expression of the $\mathrm{Cl}^{-}$transporter $\mathrm{KCC} 2$, as confirmed by the changes in the reversal potential of GABA-induced currents and the resting membrane potential after $\mathrm{GABA}_{\mathrm{A}}$ receptor blockade. We found that radial migration to layer II/III of the somatosensory cortex of neurons derived from the transfected progenitors was not significantly affected, but their morphological maturation was markedly impaired. Furthermore, reducing neuronal excitability of cortical neurons in vivo by overexpressing an inward-rectifying $\mathrm{K}^{+}$channel, which lowered the resting membrane potential, mimicked the effect of premature KCC2 expression. Thus, membrane depolarization caused by early GABA excitation is critical for morphological maturation of neonatal cortical neurons in vivo.
\end{abstract}

Key words: KCC2; development; radial migration; $\mathrm{K}_{\mathrm{ir}}$ 2.1; in utero electroporation; gramicidin perforated-patch

\section{Introduction}

GABA is the main inhibitory neurotransmitter in the adult mammalian brain and exerts its effects through the activation of both ionotropic and metabotropic GABA receptors. However, GABA produces excitatory actions in the embryonic and neonatal brain (Ben-Ari, 2002). In vitro studies have suggested that early GABA action may serve trophic functions, including cell proliferation, neuronal migration, and neurite growth (Represa and Ben-Ari, 2005), but in vivo evidence for these functions has been elusive. The early excitatory action of GABA is attributable to a high intracellular $\mathrm{Cl}^{-}$concentration $\left(\left[\mathrm{Cl}^{-}\right]_{\mathrm{i}}\right)$, which sets the reversal potential for $\mathrm{Cl}^{-}$currents $\left(E_{\mathrm{Cl}}\right)$ through $\mathrm{GABA}_{\mathrm{A}}$ receptors at a level more positive than the resting potential. Developmental upregulation of the neuron-specific $\mathrm{K}^{+}-\mathrm{Cl}^{-}$cotransporter KCC2 lowers $\left[\mathrm{Cl}^{-}\right]_{\mathrm{i}}$ (Rivera et al., 1999; DeFazio et al., 2000) during the postnatal period, resulting in a hyperpolarizing shift in $E_{\mathrm{Cl}}$ and a conversion of GABA action from excitation to inhibition. In embryonic and neonatal neurons, GABA-induced membrane depolarization may generate action potentials, activate voltage-dependent $\mathrm{Ca}^{2+}$ channels, and facilitate opening of NMDA receptors, leading to a rise of the intracellular $\mathrm{Ca}^{2+}$ concentration and activation of a wide-range of $\mathrm{Ca}^{2+}$-dependent processes during development.

\footnotetext{
Received Nov. 29, 2006; revised March 7, 2007; accepted March 26, 2007.

This work was supported by National Institutes of Health Grant NS36999. H.F. was supported in part by a fellowship from the Swiss National Science Foundation. We are indebted to Y.-x. Diing and X.-b. Yuan of the Institute of Neuroscience (Shanghai, China) for introducing us to the in utero electroporation, C. Mouri and J. Jou for help with data analysis, and M. Shelley for help in surgery.

*L.C. and H.F. contributed equally to this work.

Correspondence should be addressed to Mu-ming P0o at the above address. E-mail: mpoo@berkeley.edu. DOl:10.1523/JNEUROSCI.5169-06.2007

Copyright $\odot 2007$ Society for Neuroscience $\quad$ 0270-6474/07/275224-12\$15.00/0
}

Newly born cortical neurons undergo extensive migration before reaching their final destination in the brain. In rodents, glutamatergic neurons are generated in the ventricular zone (VZ) and subventricular zone (SVZ) of the developing cortex and migrate under the guidance of radial glia toward the developing cortical plate $(\mathrm{CP})$, leading to the formation of the characteristic layered structure of the cortex (Kriegstein, 2005). In cultures of cortical slices, GABA receptor activation influenced the movement and migration of immature cortical neurons (Owens and Kriegstein, 2002); activation of $\mathrm{GABA}_{\mathrm{C}}$ and $\mathrm{GABA}_{\mathrm{B}}$ receptors promoted migration out of the $\mathrm{VZ}$ and intermediate zone (IZ), respectively, whereas $\mathrm{GABA}_{\mathrm{A}}$ receptor activation provided a stop signal once the cell reached the CP (Behar et al., 1996, 1998, 2000, 2001). Some of the GABA effects on migration required membrane depolarization and $\mathrm{Ca}^{2+}$ elevation (Behar et al., 1996, 1998), consistent with the excitatory action of GABA in developing neurons. In addition to the effects on migration, neurite growth was influenced by $\mathrm{GABA}_{\mathrm{A}}$ receptor activation in various systems (Barbin et al., 1993; Marty et al., 1996; Maric et al., 2001; Tapia et al., 2001; Borodinsky et al., 2003), an effect that could be reproduced by agents that elevate GABA synthesis or activate L-type $\mathrm{Ca}^{2+}$ channels (Maric et al., 2001; Tapia et al., 2001; Borodinsky et al., 2003). Interestingly, neurite growth could also be antagonized by furosemide, which inhibits $\mathrm{Cl}^{-}$transporters (Maric et al., 2001), again suggesting the involvement of $\mathrm{GABA}_{\mathrm{A}}$ receptor activation and $\mathrm{Ca}^{2+}$ elevation.

Despite the documented in vitro effects of excitatory GABA, the role of GABA excitation in early cortical development in vivo has been unclear. Mice with genetic deletion of key genes of the GABAergic system exhibited no obvious defects in brain development (Asada et al., 1997; Ji et al., 1999; Heinen et al., 2003), although detailed morphological examination of cortical neu- 
rons has not been performed for these mice. In the present study, we used in utero electroporation to specifically eliminate the excitatory action of endogenous GABA on a subpopulation of newly born cortical neurons, by shifting the $E_{\mathrm{Cl}}$ through premature expression of KCC2, to determine whether in vitro actions of excitatory GABA also exist in vivo for cortical neurons in their native environment. We found that eliminating excitatory GABA action resulted in severe impairment of the morphological maturation of cortical neurons in vivo, without significant effect on their radial migration.

\section{Materials and Methods}

In utero electroporation. Timed-pregnant Sprague Dawley rats (Charles River Laboratories, Wilmington, MA) were anesthetized at stage embryonic day 17 (E17) to E18 with isoflurane (3.5\% during induction, 2.5\% during surgery), and the uterine horns were exposed by way of a laparotomy. Saline solution containing the expression vector of interest $(2 \mathrm{mg} /$ $\mathrm{ml})$ together with the dye Fast Green $(0.3 \mathrm{mg} / \mathrm{ml}$; Sigma, St. Louis, MO) was injected $(1-2 \mu \mathrm{l})$ through the uterine wall into one of the lateral ventricles of the embryos using a 30.5 ga needle (BD Biosciences, San Jose, CA). Each embryo's head was held between tweezer-type circular electrodes (diameter, $1 \mathrm{~cm}$; model 522; Harvard Apparatus, Holliston, MA) across the uterus wall and five electrical pulses (amplitude, $50 \mathrm{~V}$; duration, $50 \mathrm{~ms}$; intervals, $100 \mathrm{~ms}$ ) were delivered with a square-wave electroporation generator (model ECM 830; Harvard Apparatus). The uterine horns were then returned into the abdominal cavity, the wall and skin were sutured, and embryos were allowed to continue their normal development. Control embryos electroporated with the enhanced green fluorescent protein (EGFP) construct and embryos electroporated with KCC2/EGFP or $\mathrm{K}_{\mathrm{ir}}$ /EGFP construct (for definitions, see below, Expression vectors) were obtained from the same litter, and the injections were made on the left and right ventricles, respectively, for later identification. The $\mathrm{K}_{\mathrm{ir}} / \mathrm{EGFP}$ construct was coelectroporated with a vector expressing YFP (yellow fluorescent protein). In a set of control experiments, a vector expressing Tomato (for definition, see below, Expression vectors) was cotransfected together with either EGFP or KCC2/EGFP. All animal protocols were approved by the Animal Care and Use Committee of the University of California at Berkeley.

Expression vectors. The cDNA encoding KCC2 was cloned into pCAGIRES-EGFP (gift from X. Zhang, Institute of Neurosciences, Shanghai, China). The pCAG-Kir2.1-IRES-EGFP vector was a gift from C. Wang (Institute of Neurosciences, Shanghai, China), and pCAG-IREStdTomato was created by substituting tdTomato (gift from R. Tsien, University of California, San Diego, La Jolla, CA) for EGFP in pCAGIRES-EGFP constructs. The expressing vectors pCAG-IRES-EGFP, pCAG-KCC2-IRES, pCAG-Kir2.1-IRES-EGFP, and pCAG-IREStdTomato are thereafter termed "EGFP," "KCC2/EGFP," "Kir2.1/ EGFP," and "Tomato," respectively. These constructs bear a modified chicken $\beta$-actin promoter with a cytomegalovirus-immediate early enhancer, which confers high and long-lasting in vivo expression of both the protein of interest and EGFP. Rat KCC2 cDNA has been described previously (Fiumelli et al., 2005). As a control, we generated the loss-offunction mutant C568A-KCC2 with the QuikChange XL site-directed mutagenesis kit (Stratagene, La Jolla, CA). The same substitution of this conserved cysteine (568 in rat) has been previously shown to render the human KCC2 inactive under both isotonic and hypotonic conditions when expressed in Xenopus oocytes (Reynolds et al., 2004).

Immunostaining. Perinatal (E18-P1) brains were fixed directly in $4 \%$ paraformaldehyde/PBS. Postnatal $(\geq \mathrm{P} 2)$ brains were fixed by transcardial perfusion of $4 \%$ paraformaldehyde/PBS. Brains were sectioned coronally with a vibratome (model 3000 ; Vibratome, St. Louis, MO) at the level of the somatosensory cortex, and the slices $(70 \mu \mathrm{m})$ were immunostained as free-floating sections. Samples were permeabilized in $0.3 \%$ Triton X-100/PBS and blocked in PBS containing 5\% NGS and $0.1 \%$ BSA. Primary antibodies (rabbit anti-KCC2, 1:200; mouse anti-GFP, 1:500; mouse anti-neuronal nuclei (NeuN), 1:500; Millipore, Billerica, MA) were incubated in the block solution. Immunostaining was detected using fluorescently conjugated secondary antibodies [Alexa 488 and Al- exa 568 (Invitrogen, San Diego, CA); Cy5 (cyanine 5), $2 \mu \mathrm{g} / \mathrm{ml}$ (Jackson ImmunoResearch, West Grove, PA)]. In some experiments, brain sections were counterstained with Neurotrace Nissl 640/660 (Invitrogen) Finally, samples were mounted in Vectashield (Vector Laboratories, Burlingame, CA), and examined with confocal microscopy. For experiments on migration performed at P14, the EGFP fluorescence signal was directly acquired (without GFP immunostaining) by confocal microscopy

Confocal images acquisition. For analysis of migration at E21-P6, images from sections immunostained for GFP and counterstained with Nissl staining were acquired on a confocal laser-scanning microscope (DM IRBE; Leica Microsystems, Bannockburn, IL) equipped with a $10 \times$ dry objective [numerical aperture (NA), 0.3]. Confocal images $(30-\mu \mathrm{m}$ thick $z$-stacks) of two entire slices for each experimental animal were acquired, and $Z$-series of confocal images were projected to twodimensional (2-D) representations. For analysis of cortical organization at P14, images from sections immunostained for NeuN only (no GFP immunostaining) were acquired on the confocal laser-scanning microscope equipped with a $10 \times$ dry objective (NA, 0.3). Confocal images (one single focal plane) of an entire slice for each experimental animal were acquired, and the contrast of the images was adjusted to enhance the fluorescence of cell bodies while attenuating the signal from neuronal processes to facilitate cell counting. For morphometric analysis, images from GFP-immunostained sections were acquired on the confocal laserscanning microscope equipped with a $20 \times$ oil-immersion objective (NA, $0.7)$. Confocal images $(50-\mu \mathrm{m}$-thick $z$-stacks) of three representative fields for each animal were acquired: one field in a zone of the slice with high density of transfected cells and two fields in zones of low density of transfected neurons. $Z$-series of confocal images were projected to 2-D representations, and neurites were traced and quantified with the NeuronJ software (Meijering et al., 2004) (http://rsb.info.nih.gov/ij/). The total neurite length and branch number of each individual neuron were computed. Only fields with a low density of transfected neurons were used to quantify the neuritic length and number. For each litter of animals, all sections were acquired in a random order and in a single session to minimize errors caused by fluctuation in laser output and degradation of fluorescence. The image acquisition and data analysis were performed in a blind manner.

Electrophysiology. Coronal cortical slices were prepared from rats ( $\mathrm{P} 0-$ P15) electroporated with EGFP, KCC2/EGFP, or $\mathrm{K}_{\mathrm{ir}} / \mathrm{EGFP}$, as described previously (Fiumelli et al., 2005). Whole-cell perforated-patch recordings were made from neurons in the VZ or layer II/III of the somatosensory cortex. Neurons derived from electroporated progenitor cells were identified by EGFP fluorescence using an upright fluorescence microscope (E600 FN; Nikon, Tokyo, Japan). Glass micropipettes (resistance, 3-5 M $\Omega$ ) were tip-filled with an internal solution of $150 \mathrm{~mm} \mathrm{KCl}$ or $\mathrm{CsCl}$ and 10 mM HEPES ( $\sim 300 \mathrm{mOsm}, \mathrm{pH} 7.3$ ) and back-filled with the same solution containing $40 \mu \mathrm{g} / \mu \mathrm{l}$ gramicidin A (Sigma). For experiments using amphotericin $\mathrm{B}$, pipettes were tip-filled with an internal solution consisting of (in mM) 154 K-Gluconate, $9 \mathrm{NaCl}, 1 \mathrm{MgCl}_{2}, 1 \mathrm{HEPES}$, and 0.2 EGTA, and then back-filled with the same internal solution containing amphotericin B $(200 \mu \mathrm{g} / \mathrm{ml}$; EMD Biosciences, La Jolla, CA $)$. The external bath solution contained (in mM) $124 \mathrm{NaCl}, 2.8 \mathrm{KCl}, 2 \mathrm{MgSO}_{4}$ $1.25 \mathrm{NaH}_{2} \mathrm{PO}_{4}, 2 \mathrm{CaCl}_{2}, 26 \mathrm{NaHCO}_{3}$, and 12 D-glucose ( $\sim 310 \mathrm{mOsm}$, $\mathrm{pH}$ 7.4), was oxygenated with $95 \% \mathrm{O}_{2}$ and $5 \% \mathrm{CO}_{2}$, and was used for continuous perfusion $(1.5 \mathrm{ml} / \mathrm{min})$ of the slices at $22^{\circ} \mathrm{C}$. In some experiments, TTX ( $1 \mu \mathrm{M}$; Sigma) and $\mathrm{LaCl}_{3}$ (30 $\mu \mathrm{M}$; Sigma) were added to the extracellular solution to block voltage-gated $\mathrm{Na}^{+}$and $\mathrm{Ca}^{2+}$ currents, respectively. Recordings were made with a patch-clamp amplifier (Axopatch multiclamp 700A; Molecular Devices, Union City, CA); data were sampled at $10 \mathrm{kHz}$, filtered at $5 \mathrm{kHz}$, and analyzed with pClamp 8.0 software (Molecular Devices). The $E_{\mathrm{Cl}}$ in $\mathrm{P} 0$ and P1 VZ neurons was estimated by measuring the peak depolarization/hyperpolarization produced by a saturating puff of GABA ( $1 \mathrm{~mm} ; 20 \mathrm{~ms}$; Sigma) applied at the soma of the cell with a micropipette coupled to an electrically gated pressure valve (picospritzer), using gramicidin perforated-patch recordings in current-clamp mode. For each experiment, $E_{\mathrm{Cl}}$ measurements were performed in triplicate at $1 \mathrm{~min}$ intervals. In some cases, two repeats with membrane potential current clamped at two different potentials were performed with a 1 min interval. To determine the $E_{\mathrm{Cl}}$ in $\mathrm{P} 4-\mathrm{P} 15$ 
animals, we performed gramicidin perforatedpatch recordings in voltage-clamp mode. The holding potential was varied in $10 \mathrm{mV}$ increments and measurements of IPSC amplitudes in response to exogenous GABA pulses (100 $\mu \mathrm{M} ; 20-50 \mathrm{~ms}$; at $15 \mathrm{~s}$ intervals) applied near the soma were performed. Linear regression was used to calculate a best-fit line for the voltage dependence of GABA-induced currents, and the interpolated intercept of this line with the abscissa was taken as the $E_{\mathrm{Cl}}$ value. For each experiment, $E_{\mathrm{Cl}}$ measurements were performed in triplicate at $3 \mathrm{~min}$ intervals. All recordings were terminated and data were discarded if the series resistance varied by $>15 \%$ during the course of the experiment or if the perforated patch spontaneously ruptured into whole-cell configuration, as evidenced by an $E_{\mathrm{Cl}}$ of $\sim 0 \mathrm{mV}$ or large depolarizing currents recorded in current- or voltage-clamp mode, respectively. To characterize tonic endogenous GABAinduced currents, we substituted $\mathrm{KCl}$ with $\mathrm{CsCl}$ in the gramicidin internal solution and recorded the membrane current $\left[V_{c}\right.$ (clamping voltage), $-60 \mathrm{mV}$; filtered at $2 \mathrm{kHz}$ ] before and after bath addition of $150 \mu \mathrm{M}$ bicuculline (Sigma). To quantify the number of spikes, cells were recorded in current-clamp mode after whole-cell configuration was established in voltage-clamp mode. Cells were injected with depolarizing step currents (4 pA increments; 300 ms duration). To generate the "input-output curve", the mean number of spikes for each current injection step was obtained from each experiment performed in triplicate. Resting membrane potentials were measured in the absence of current injection.

Statistical analysis. Statistical analysis was performed with $t$ test or ANOVA and post hoc comparison. For datasets of non-normal distribution, the nonparametric Kruskal-Wallis one-way ANOVA test was used. All results were expressed as mean \pm SEM.

\section{Results}

Premature KCC2 expression in newly born cortical neurons in vivo

In the developing rat neocortex, postnatal expression of KCC2 results in the switch of GABA action from excitation to inhibition by the end of the second postnatal week

(Owens et al., 1996; Clayton et al., 1998). In immature cultured neurons, we have shown that KCC2 overexpression shifts $E_{\mathrm{Cl}}$ toward more negative values and prevents GABA-induced $\mathrm{Ca}^{2+}$ elevation (Fiumelli et al., 2005). In the present study, we aimed for an early termination of GABA excitation in vivo by premature expression of KCC2 in a subpopulation of newly generated cortical neurons. We injected a bicistronic construct encoding KCC2 and EGFP or an EGFP construct into the lateral ventricle of E17E18 rat embryos and transferred it into neural progenitor cells by in utero electroporation (Saito and Nakatsuji, 2001). After allowing normal embryonic development in vivo, immunostaining for KCC2 and GFP was performed on brain slices obtained from $\mathrm{P} 0-\mathrm{P} 1$ rats. High-level expression of EGFP was detectable in some neurons for rats transfected with KCC2/EGFP or with EGFP alone (Fig. 1a,b). Strong KCC2 staining, which colocalized with EGFP fluorescence (Fig. 1b), was present in CP and VZ of

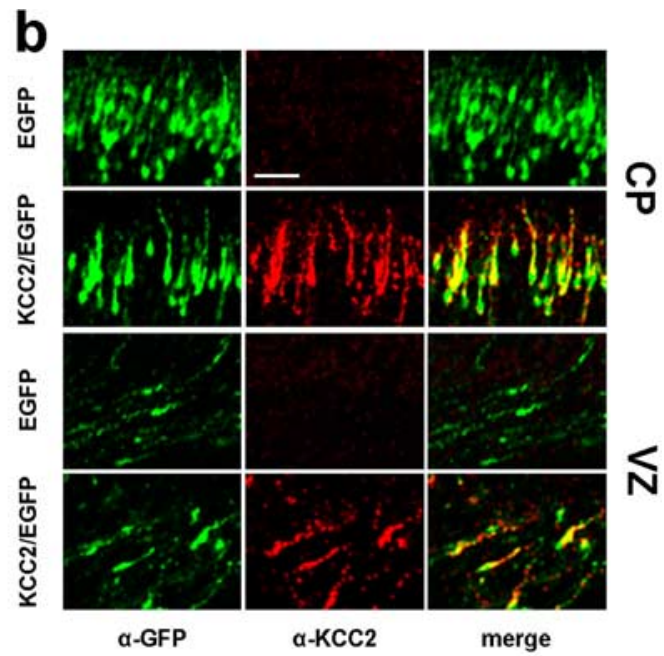

e

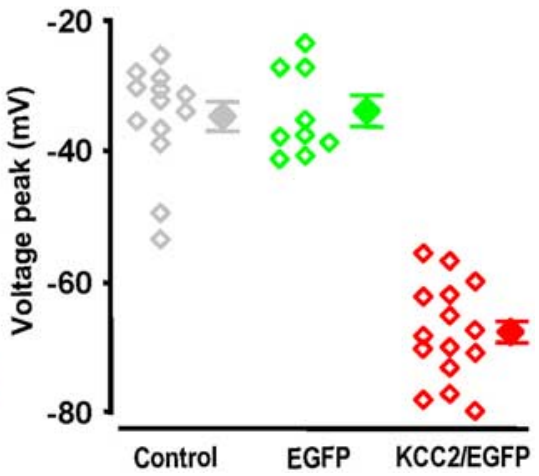

Figure 1. Premature expression of KCC2 in cells in the VZ caused a positive shift in $E_{\mathrm{Cl}} \cdot \boldsymbol{a}$, Confocal images of coronal sections of somatosensory cortices of $\mathrm{PO}$ rats transfected via in utero electroporation with EGFP or KCC2/EGFP construct and immunostained (1) measurements at P0. $\boldsymbol{d}$, Examples of membrane voltage responses elicited by puffing saturating concentration of GABA at the soma of VZ cells in acute slices of somatosensory cortex from P0 and P1 rats, which were transfected with KCC2/EGFP (red) or EGFP (gre same slices were used as the control (gray). Two repeats with membrane potential current clamped at two different potentials were performed with a $1 \mathrm{~min}$ interval. Calibration: $500 \mathrm{~ms}, 10 \mathrm{mV}$. e, $E_{\mathrm{Cl}}$ values estimated by GABA puffing for $\mathrm{PO}$ and $\mathrm{P} 1$ untransfected control neurons (gray) or neurons transfected with EGFP only (green) or with KCC2/EGFP right. Data for KCC2/EGFP-transfected cells were significantly different from those for untransfected (control) or EGFP-transfected cells ( $p<0.001$, one-way ANOVA; $p<0.05$, post hoc Holm-Sidak method).

KCC2/EGFP-transfected cortices, indicating that endogenous KCC2 is expressed at a very low level at P0 and that in utero electroporation allowed premature expression of KCC2 in a subpopulation of $\mathrm{VZ}$ progenitors and those cortical neurons derived from these cells (Fig. 1b).

Eliminating GABA excitation by premature KCC2 expression The effectiveness of premature KCC2 expression in eliminating GABA excitation was examined by estimating $E_{\mathrm{Cl}}$ with gramicidin perforated-patch recording (Kyrozis and Reichling, 1995) in cells in the VZ of acute cortical slices from P0-P1 rats that were electroporated with either KCC2/EGFP or EGFP constructs at E18 (Fig. 1c). Gramicidin forms membrane pores permeable to monovalent cations and small uncharged molecules but not to $\mathrm{Cl}^{-}$, thereby leaving $\left[\mathrm{Cl}^{-}\right]_{\mathrm{i}}$ undisturbed and permitting a reliable estimate of $E_{\mathrm{Cl}}$. Because the proliferating VZ cells are electrically 
a
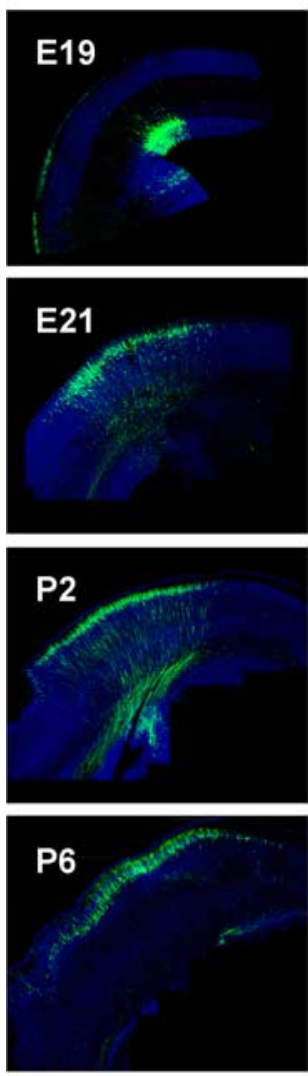

EGFP
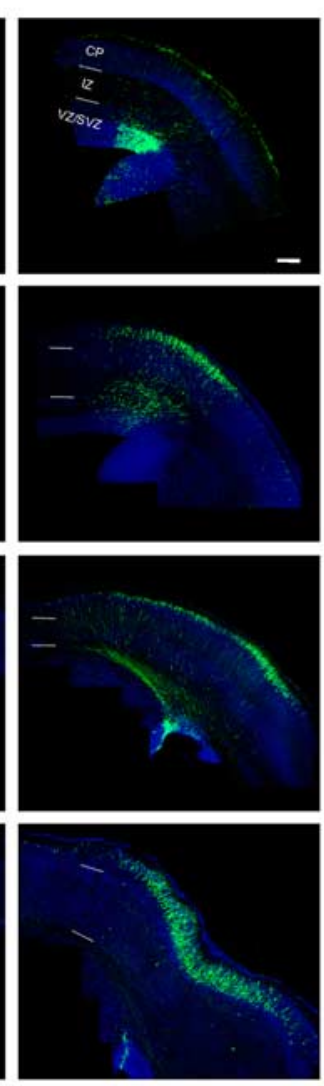

KCC2/EGFP b
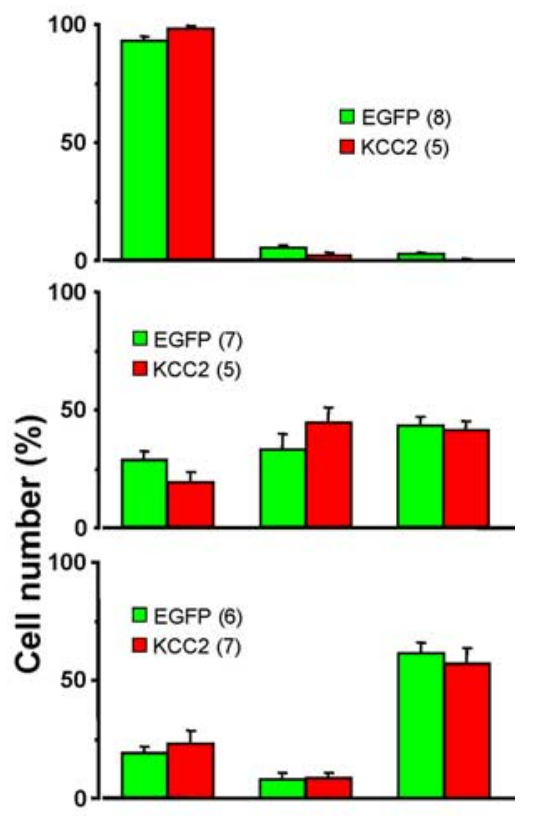

100

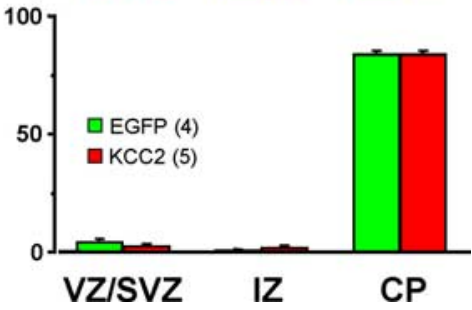

Figure 2. Premature expression of KCC2 did not affect neuronal migration. $\boldsymbol{a}$, Representative confocal images of coronal sections of rat somatosensory cortex at different days after in utero electroporation of the EGFP or KCC2/EGFP construct (at E17). Sections were immunostained for GFP (green) and counterstained with fluorescent Nissl stain (blue). White dotted lines mark boundaries between different regions of the developing cortex. Scale bar, $200 \mu \mathrm{m}$. $\boldsymbol{b}$, Quantification of the number of neurons expressing either EGFP only (green) or KCC2/EGFP (red) residing at the VZ, IZ, or CP (marked in $a$ ) at different developmental ages, as a percentage of the total number of fluorescent cells in the same section. Data represent mean \pm SEM. Data for KCC2/EGFP cells were not significantly different from those for EGFP-only cells observed at all ages ( $p>0.001$, one-way ANOVA). Numbers in parentheses refer to the total number of rats processed.

coupled through gap junctions (LoTurco et al., 1995) and therefore difficult to voltage clamp, we estimated $E_{\mathrm{Cl}}$ in $\mathrm{VZ}$ cells using current clamp (Owens et al., 1996) by measuring the peak depolarization or hyperpolarization produced by a saturating dose of GABA (1 mM; $20 \mathrm{~ms}$ ) at the cell soma. Bath application of TTX (1 $\mu \mathrm{M})$ and $\mathrm{La}^{3+}(30 \mu \mathrm{M})$ were used to block $\mathrm{Na}^{+}$and $\mathrm{Ca}^{+}$currents, respectively, and $\mathrm{Cs}^{+}(150 \mathrm{~mm})$ was present in the internal solution of the microelectrode to block $\mathrm{K}^{+}$channels. In these conditions, the value of the peak membrane potential induced by the GABA pulse represents an estimate of $E_{\mathrm{Cl}}$ (Owens et al., 1996). As shown by the example recordings in Figure $1 d$, we found that the GABA pulse induced depolarization of the membrane potential to approximately $-35 \mathrm{mV}$ in both untransfected control cells and cells expressing EGFP alone, whereas the same GABA pulse induced hyperpolarization to approximately $-70 \mathrm{mV}$ in KCC2/ EGFP-expressing cells. Summary of all recordings showed that premature KCC2 expression resulted in a shift of $E_{\mathrm{Cl}}$ from $-34.9 \pm 2.3 \mathrm{mV}$ in control cells to $-67.9 \pm 1.9 \mathrm{mV}$ in KCC2 cells (Fig. 1e), a value close to that attained during normal development (for comparison, see Fig. $5 c$ ) and more negative than the resting membrane potential $(-54.7 \pm 1.4 \mathrm{mV} ; n=5$; KCC2 cells), consistent with a conversion of GABA action from excitation to inhibition.

Neuronal migration is unaffected by eliminating GABA excitation in vivo The functional consequence of premature KCC2 expression on cortical development was first examined for the radial migration of newly generated cortical neurons over a period ranging from E18 to P6. At E19, 2 d after electroporation, EGFP-labeled cells in coronal slices of the somatosensory cortex were found almost exclusively in the VZ and SVZ (Fig. 2a). By E21, EGFP cells appeared to spread across the cortex from the VZ to the CP (Fig. 2a). During the first few postnatal days, the percentage of EGFP cells reaching the $\mathrm{CP}$ increased gradually, with essentially all fluorescent cells residing in layer II/III by P6 (Fig. 2a). At all ages examined, we found no significant difference in the distribution and total number of cells expressing either KCC2/EGFP or EGFP alone (Fig. $2 b$ ). We note that, as indicated by the $E_{\mathrm{Cl}}$ measurements described above for $\mathrm{VZ}$ cells in $\mathrm{P} 0-\mathrm{P} 1$ cortices, KCC2/EGFP-transfected cells were unlikely to experience any GABA excitation during the course of their radial migration.

To study in more detail whether excitatory GABA was important in the fine cortical layering of the cortex, we examined animals at P14 when the characteristic sixlayer structure of the somatosensory cortex was clearly discernible (Fig. $3 a, b$ ). As shown in Figure $3 a$, we did not find any significant difference in the distribution of KCC2/EGFP or EGFP neurons across the cortical layers at P14. To quantify the number of cells that reached the different cortical layers, sections of the somatosensory cortex were immunostained for the neuronal marker NeuN, and cells stained positive for NeuN and expressing EGFP were counted along the cortical thickness (Fig. 3b,d). We found that the distribution of KCC2/EGFP-expressing neurons was similar to that of EGFPexpressing cells (Fig. $3 b-d$ ). Normalization for the variation of neuronal density in different layers, as revealed by NeuN staining, further indicated a selective but similar accumulation of KCC2/ EGFP and EGFP-expressing neurons in layer II/III (Fig. 3e). Thus, premature switch from GABAergic excitation to inhibition did not affect radial migration and cortical distribution of the subpopulation of cortical neurons that were derived from progenitor cells transfected at E17 or E18.

\section{GABA excitation is critical for morphological maturation of cortical neurons in vivo}

We then investigated whether the morphology of KCC2/EGFPexpressing neurons was affected at P4-P6, when the level of endogenous KCC2 expression remains low in control animals, but neurons have completed their radial migration and started to exhibit complex dendritic arborization (Fig. 4a). Measurements of $E_{\mathrm{Cl}}$ were performed on KCC2/EGFP- and EGFP-expressing neurons as well as untransfected cells in layer II/III by examining the current-voltage relationship of GABA-induced currents at the cell body, under the voltage-clamp condition. We found that, 
compared with control cells, KCC2/EGFP expression resulted in more negative $E_{\mathrm{Cl}}(-72.1 \pm 2.3 \mathrm{mV}$ in KCC2-overexpressing cells; $-52.1 \pm 2.2 \mathrm{mV}$ in control neurons) (Fig. $4 b, c$ ). Because the average resting potential was $-64.7 \pm 1.0 \mathrm{mV}$ $(n=21)$ in KCC2/EGFP cells and $-60.0 \pm$ $1.5 \mathrm{mV}(n=33)$ in control cells, the GABA action would be excitatory for controls and inhibitory for KCC2/EGFP-transfected neurons. Moreover, although premature KCC2 expression had no significant effect on the radial migration of cortical neurons, morphological maturation of these neurons after their arrival at layer II/III was greatly affected. At P6, KCC2-expressing cells exhibited fewer and shorter dendritic processes, with very few of them projecting into layer I, compared with control cells expressing EGFP alone (Fig. $4 d$ ). Projected images of typical neurons (Fig. 4e) and samples of reconstructed neurons (Fig. $4 f$ ) all showed pronounced reduction in the total neurite length and branch number in KCC2/ EGFP-expressing cells, compared with cells expressing EGFP only (Fig. $4 g$ ).

We also examined the morphology of KCC2/EGFP-expressing neurons at P14, when the GABA switch from excitation to inhibition is completed (Owens et al., 1996) and the effect of premature KCC2 expression is likely to have been accumulated. We found that at P14, endogenous KCC2 expression was higher than that found in P6 animals (compare Figs. 4a, $5 a$ ), although the level in EGFP-expressing cells remained lower than that in KCC2/ EGFP-expressing cells. Interestingly, the $E_{\mathrm{Cl}}$ found in control P14 animals was not significantly different from that attained in KCC2/EGFP-overexpressing cells (Fig. $5 b, c)$, indicating that overexpressing KCC2 had set a rather physiological $E_{\mathrm{Cl}}$ in these neurons. As shown in Figure $5 d$, the morphological impairment of KCC2/ EGFP-overexpressing cells found at P14 was more pronounced than that found at P6 (for comparison, see Fig. 4d). Projected images of typical transfected neurons (Fig. $5 e$ ) and samples of reconstructed neurons (Fig. 5f) at P14 all showed pronounced reduction in the total neurite length and branch number in KCC2/EGFPexpressing cells, compared with cells expressing EGFP only (Fig. $5 g$ ). Thus, the disrupted morphological maturation of cortical neurons caused by premature KCC2 expression had persisted in P14 animals after the high-level expression of endogenous KCC2 had occurred.

The apparent morphological impairment described above was not attributable to the use of the bicistronic construct that drove KCC2 expression upstream of EGFP, a condition that may have resulted in a reduced efficiency of EGFP expression, leading

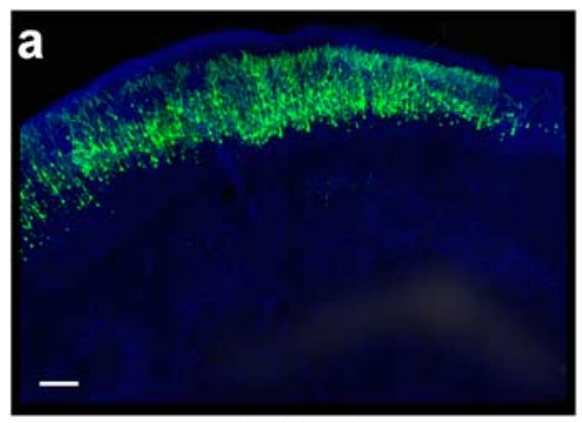

EGFP

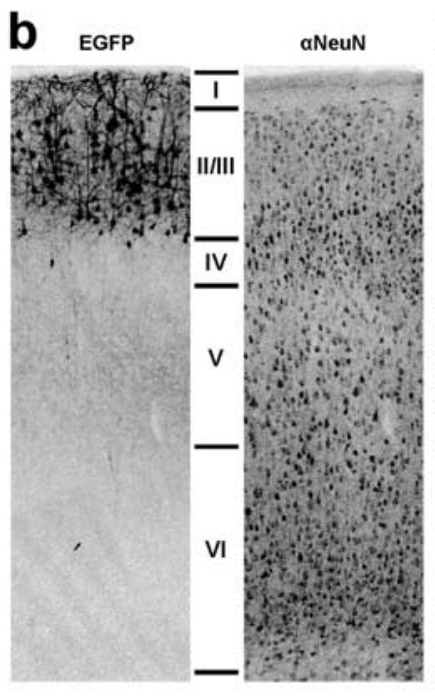

EGFP

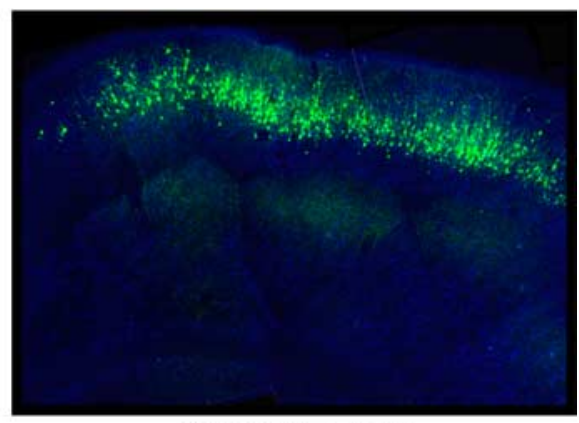

KCC2/EGFP e

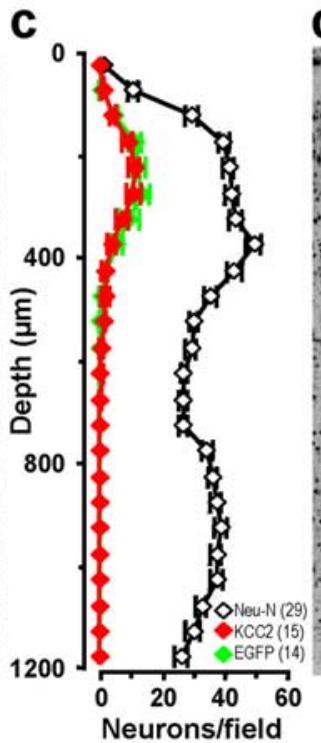

d aneuN

EGFP

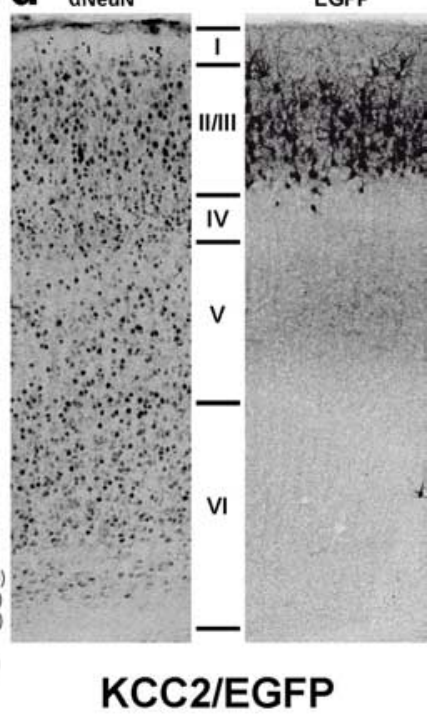

KCC2/EGFP

Figure 3. Premature expression of KCC2 did not affect cortical layering. $\boldsymbol{a}$, Confocal images of coronal sections of P14 somatosensory cortex of rat transfected via in utero electroporation with KCC2/EGFP or EGFP. Slices were stained for the neuronal marker NeuN (blue) to highlight cortical layers. Scale bar, $200 \mu \mathrm{m}$. $\boldsymbol{b}$, Representative images of EGFP fluorescence and NeuN immunofluorescence for a typical section of a P14 rat transfected with EGFP. $c$, The number of EGFP ${ }^{+}$cells (in $50 \mu \mathrm{m}$ bins) with respect to cortical depth in the EGFP and KCC2/EGFP-transfected animals. The number of $\mathrm{NeuN}^{+}$cells was obtained by averaging the sections from KCC2/EGFP and EGFP animals, because they were not significantly different ( $p>0.001$, two-way ANOVA). $\boldsymbol{d}$, Representative images of a typical section of a P14 rat transfected with KCC2/EGFP as in $\boldsymbol{b}$. $\boldsymbol{e}$, Accumulation of EGFP ${ }^{+}$cells in different cortical layers, as indicated by the ratio of EGFP ${ }^{+}$and $\mathrm{NeuN}^{+}$cells at each $50 \mu \mathrm{m}$ bin (from dataset in c) along the cortical axis. Numbers in parentheses represent the total number of rats analyzed.

to a poor resolution of dendritic processes in KCC2/EGFPexpressing cells compared with cells expressing EGFP only. This possibility was excluded by cotransfecting a plasmid carrying a red fluorescent protein (Tomato) sequence together with KCC2/ EGFP or EGFP. For cells that expressed both Tomato and KCC2/ EGFP or EGFP, we found that the neuronal morphology revealed by the green and red fluorescence was identical (supplemental Fig. S1, available at www.jneurosci.org as supplemental material). Thus, the morphological impairment in KCC2/EGFP- 
a
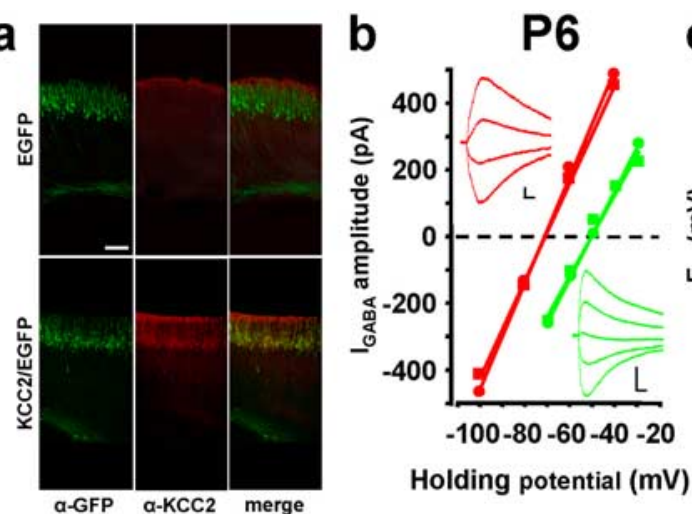

Holding potential ( $\mathrm{mV}$ )

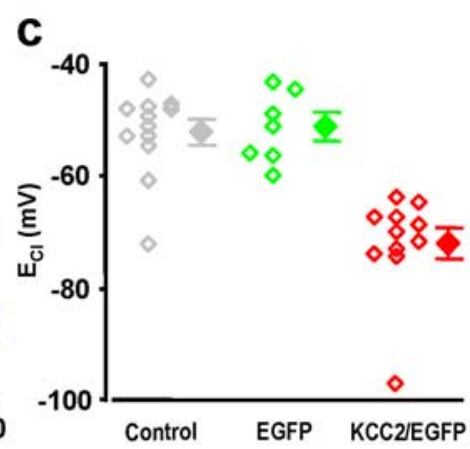

e

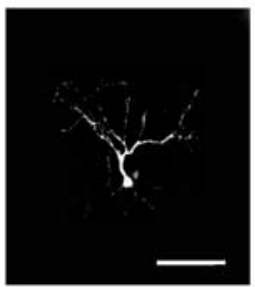

EGFP

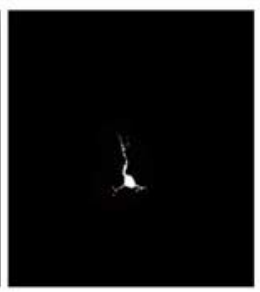

KCC2/EGFP
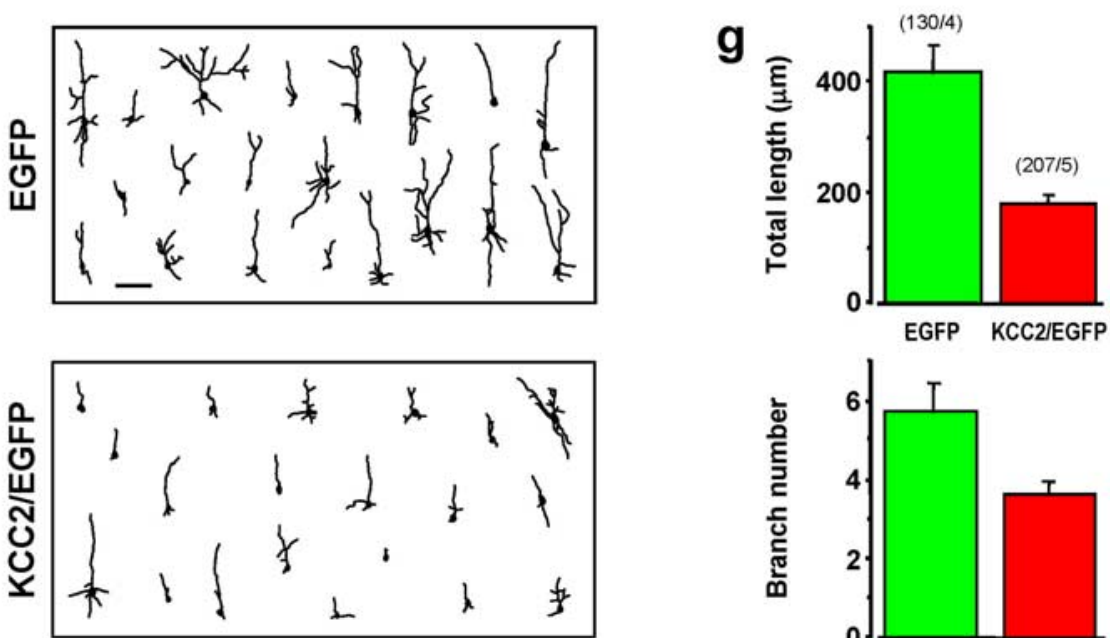

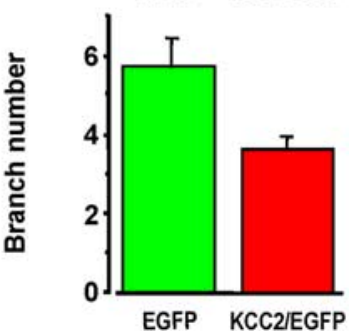

Figure 4. GABA excitation was essential for morphological maturation. $\boldsymbol{a}$, Confocal images of coronal sections of somatosensory cortices of $\mathrm{P} 4$ rats transfected via in utero electroporation with or KCC2/EGFP construct and immunostained for GFP and KCC2. Scale bar, $200 \mu \mathrm{m} . \boldsymbol{b}$, Examples of $/-V$ relationships for membrane current responses elicited by puffing GABA at the soma of layer II/III neurons in acute slices of somatosensory cortex from P4-P6 rats, which were transfected with KCC2/EGFP (red, 2 repeats spaced by $3 \mathrm{~min}$ ) or EGFP (green). Insets, Sample traces of GABA-induced currents at different holding potentials. Calibration: 100 $\mathrm{ms}, 100 \mathrm{pA}$. c, $E_{\mathrm{Cl}}$ values determined by GABA puffing for P4-P6 neurons untransfected (gray) or transfected with EGFP only (green) or with KCC2/EGFP (red). Data points represent results from single neurons (open diamonds), and the average value ( \pm SEM) is indicated on the right. Data for KCC2/EGFP-transfected cells were significantly different from that of untransfected (control) or EGFP-transfected cells ( $p<0.001$, one-way ANOVA; $p<0.05$, post hoc Holm-Sidak method). d, Representative GFP immunostaining showing regions with a high density of EGFP-expressing neurons in layer II/III coronal sections of P6 somatosensory cortices, which were transfected with EGFP and KCC2/EGFP. Scale bar, $100 \mu \mathrm{m}$. $\boldsymbol{e}$, Examples of the 2-D projection of confocal images of single neurons at $P 6$ in regions with a low density of EGFP-expressing cells, from sections of rat cortices transfected with EGFP or KCC2/EGFP. Scale bar, $100 \mu \mathrm{m}$. $\boldsymbol{f}$, Tracing of 2-D projection of the dendritic arbor of 20 randomly sampled neurons in layer II/III of P6 cortices transfected with EGFP or KCC2/EGFP. Scale bar, $100 \mu \mathrm{m}$. $\boldsymbol{g}$, Total dendritic length and branch number of cortical neurons at P6 transfected with EGFP or KCC2/EGFP. Data represent mean \pm SEM. For both parameters, the values of KCC2/EGFPtransfected cells were different from those of EGFP-transfected cells ( $p<0.001$, Kruskal-Wallis one-way ANOVA; $p<0.05$, post hoc Dunn's method). Numbers in parentheses refer to the total number of cells/rats analyzed.

transfected neurons was not attributable to poor EGFP expression of the KCC2/ EGFP construct.

To test whether the observed morphological effect in KCC2/EGFP-expressing cells was caused by the specific $\mathrm{Cl}^{-}$transporter function of KCC2, we performed experiments using a mutated form of KCC2 (mtKCC2), which was defective in $\mathrm{Cl}^{-}$transporter activity (see Materials and Methods) and therefore ineffective in preventing GABA-induced $\mathrm{Ca}^{2+}$ elevation in transfected young cortical neurons in vitro (supplemental Fig. S2, available at www. jneurosci.org as supplemental material). We found that overexpression of mtKCC2 resulted in no morphological impairment of cortical neurons at P14 (Fig. 5d,g). Thus, the observed morphological effect in KCC2-transfected neurons was attributable to the altered $\mathrm{Cl}^{-}$transporter activity that eliminated the GABA excitation.

Young cortical neurons are under tonic GABA excitation

Tonic activation of $\mathrm{GABA}_{\mathrm{A}}$ receptors is evident in many brain regions of young animals (Owens et al., 1996; Farrant and Nusser, 2005). In our experimental conditions, we found that cells and processes positive for the GABA-synthesizing enzymes glutamic acid decarboxylase 65 (GAD65) and GAD67 were abundantly present across the cortex at all ages examined (supplemental Fig. S3, available at www.jneurosci.org as supplemental material), consistent with previous findings (Lauder et al., 1986; Marin-Padilla, 1998; Lavdas et al., 1999). Using gramicidin perforated-patch recording, we measured membrane currents before and after bath application of bicuculline to nontransfected (control) and KCC2/EGFPexpressing neurons $\left(V_{c},-60 \mathrm{mV}\right)$ in acute somatosensory cortical slices from P4-P6 rats that had been electroporated at E18. As shown in Figure $6 a, b$, treatment with bicuculline $(150 \mu \mathrm{M})$ resulted in an outward shift of the baseline membrane current in control neurons, revealing the presence of a tonic depolarizing current caused by endogenously secreted GABA in these slices. This is consistent with excitatory GABA actions at this stage of cortical development. In contrast, we found that in the same slices, the bicuculline treatment resulted in an inward shift of the membrane current in KCC2/EGFP-expressing neurons, consistent with the conversion of the endogenous tonic GABA action from excitation (depolarizing) to inhibition (hyperpolarizing) by premature KCC2 expression. Moreover, we found that the 
average membrane potential of control cells (EGFP-transfected and -nontransfected cells; $-60.0 \pm 1.5 \mathrm{mV} ; n=33$ ) was more depolarized than that of KCC2/ EGFP-transfected cells $(-64.7 \pm 1.0 \mathrm{mV}$; $n=21$; Student's $t$ test, $p<0.05)$, confirming the presence of a tonic GABA action on these neurons.

The small steady excitatory/inhibitory membrane current caused by tonic $\mathrm{GABA}_{\mathrm{A}}$ receptor activation was sufficient to influence action potential initiation in these young cortical neurons. We measured the number of action potentials ("output") of these cells (at P5-P6) in response to graded steps of depolarizing currents ("input") in nontransfected (control) and KCC2/EGFP-expressing cells before and after application of bicuculline (Fig. 6c). Over the same range of injected currents, control cells fired more action potentials than KCC2/EGFP-expressing cells did ( $p<0.0001$, one-way repeatedmeasures ANOVA; $p<0.05$, post hoc Holm-Sidak method). Bicuculline treatment decreased the firing of control cells but increased the firing of KCC2/EGFPexpressing cells, as indicated by the rightward versus leftward shift of the inputoutput curve, respectively (Fig. 6d). Furthermore, in younger neurons (P4), which were more resistant to excitation by depolarizing currents and in which a maximum of only one action potential could be elicited, we found that after bicuculline treatment, the current threshold for firing action potentials became higher in control neurons but lower in KCC2overexpressing neurons (data not shown). Together, these results all support the notion that tonic GABA action is excitatory in P4-P6 control cortical cells and premature KCC2 expression in these cells converts the GABA action into inhibition.

\section{$\mathrm{K}_{\mathrm{ir}} 2.1$ expression is sufficient to impair morphological maturation of cortical neurons}

If the GABA effect on morphological maturation were caused by neuronal excitation, then reducing excitation during early development should impair morphological maturation of cortical neurons. To test this hypothesis, we overexpressed the inward-rectifier $\mathrm{K}^{+}$channel $\mathrm{K}_{\mathrm{ir}} 2.1$ in newly generated cortical neurons, a manipulation that decreases neuronal excitability by hyperpolarizing the membrane potential (Hartman et al., 2006). Rat embryos were electroporated at E18 with a construct encoding $\mathrm{K}_{\mathrm{ir}}$ and EGFP, and transfected neurons were recorded in acute slices of P8 animals with amphoter-
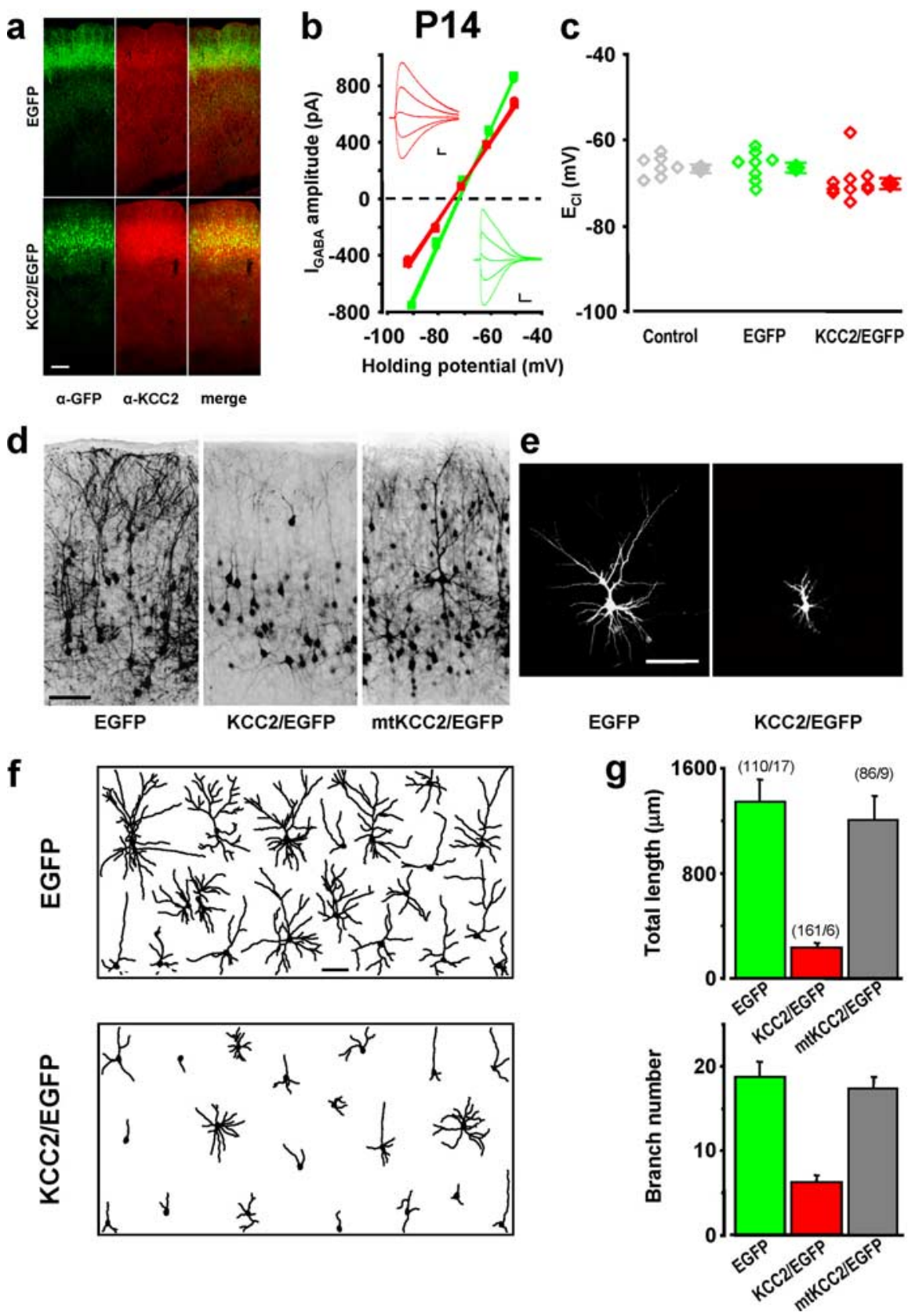

Figure 5. The effect of excitatory GABA on dendritic morphology observed at P14. a, Confocal images of coronal sections of somatosensory cortices of P14 rats transfected via in utero electroporation with EGFP or KCC2/EGFP construct and immunostained for GFP and KCC2. Scale bar, $200 \mu \mathrm{m}$. $\boldsymbol{b}$, Examples of $/-V$ relationships for membrane current responses elicited by puffing GABA at the soma of layer II/III neurons in acute slices of somatosensory cortex from P14 rats, which were transfected with KCC2/EGFP (red, 2 repeats spaced by $3 \mathrm{~min}$ ) or EGFP (green). Insets, Sample traces of GABA-induced currents at different holding potentials. Calibration: $100 \mathrm{~ms}, 100$ pA.c, $E_{C I}$ values determined by GABA puffing for P14 and P15 neurons untransfected (gray) or transfected with EGFP only (green) or with KCC2/EGFP (red), presented similarly to those of Figure 4c. Data for KCC2/EGFP cells were not significantly different from those for control or EGFP cells ( $p>0.001$, one-way ANOVA). $\boldsymbol{d}$, Representative GFP immunostaining showing regions with a high density of EGFP-expressing neurons in layer II/III coronal sections of P14 somatosensory cortices, which were transfected with EGFP, KCC2/EGFP, or mtKCC2/EGFP. Scale bar, $100 \mu \mathrm{m}$. $\boldsymbol{e}$, Examples of the 2-D projection of confocal images of single neurons at P14 in regions with a low density of EGFP-expressing cells, from sections of rat cortices transfected with EGFP or KCC2/EGFP. Scale bar, $100 \mu \mathrm{m}$. $\boldsymbol{f}$, Tracing of the 2-D projection of the dendritic arbor of 20 randomly sampled neurons in layer II/III of P14 cortices transfected with EGFP or KCC2/EGFP. Scale bar, $100 \mu \mathrm{m} . \boldsymbol{g}$, Total dendritic length and branch number of cortical neurons at P14, transfected with EGFP or KCC2/EGFP. Data represent mean \pm SEM. For both parameters, the values of KCC2/EGFP-transfected cells were different from those of EGFP- and mtKCC2/EGFP-transfected cells ( $p<0.001$, Kruskal-Wallis one-way ANOVA; $p<0.05$, post hoc Dunn's method), but no difference was found between EGFP and mtKCC2/EGFP cells ( $p>$ 0.05). Numbers in parentheses refer to the total number of cells/rats analyzed. 
a

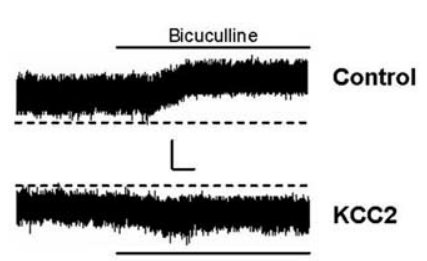

C

\section{Control}

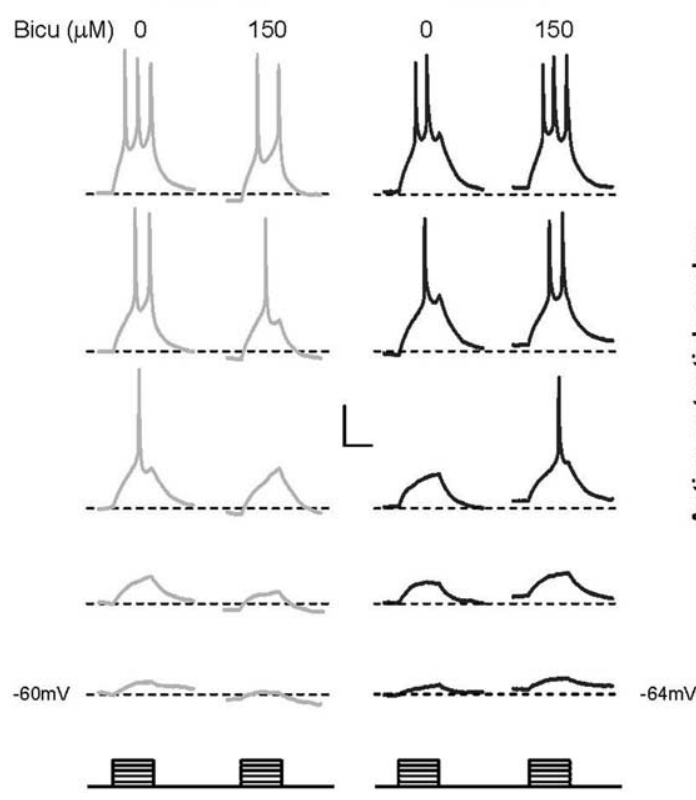

b

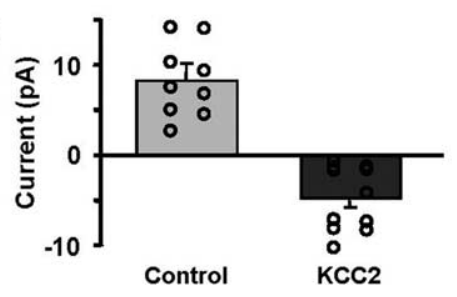

d

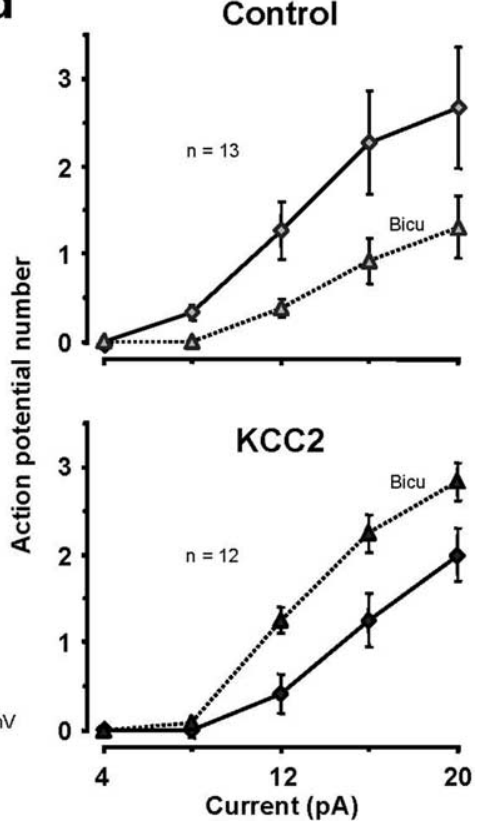

Figure 6. Measurements of tonic GABA actions on cortical neurons. a, Example recordings showing that bicuculline application (bar) resulted in a steady outward current in control cortical cells (top trace) but a steady inward current in KCC2/EGFP-expressing cells (bottom trace). Recordings were performed at P4 -P6 from neurons in layer II/III of the somatosensory cortex. Calibration: $5 \mathrm{~s}$, $10 \mathrm{pA} . \boldsymbol{b}$, Summary of all data on tonic GABA-induced currents unmasked by the application of bicuculline. Open symbols represent single cases, and histograms represent mean \pm SEM. The two sets of data were significantly different $(p<0.001, t$ test). $c$, Example recordings of membrane potential changes in untransfected control cortical cells (gray) or in KCC2/EGFP-expressing cells (black), in responses to graded (4 pA steps) depolarizing currents (bottom), before and after application of bicuculline (Bicu). Calibration: 200 ms, $20 \mathrm{mV}$. d, Input-output curves depicting the number of action potentials elicited by graded depolarizing currents before (solid line) and after (dotted line) bicuculline application, in untransfected control cells and KCC2/EGFP-expressing cells. Significant rightward and leftward shifts were found for these two groups of cells, respectively, after the bicuculline application ( $p<0.05$, Wilcoxon signed rank test). Recordings were performed at P5 and P6. $n$ refers to the total number of cells recorded.

icin perforated-patch recording. We found that overexpression of $\mathrm{K}_{\mathrm{ir}}$ resulted in a membrane potential $(-76.9 \pm 1.8 \mathrm{mV} ; n=$ 15) substantially more negative than that of control neurons from the same slices $(-59.4 \pm 1.2 \mathrm{mV} ; n=11)$. Furthermore, $\mathrm{K}_{\mathrm{ir}}$-transfected cells exhibited fewer spikes in response to graded steps of depolarizing currents (Fig. 7a) and an input-output curve shifted significantly toward the right (Fig. 7b). Importantly, compared with cortical cells expressing EGFP alone, $\mathrm{K}_{\mathrm{ir}}{ }^{-}$ transfected cells showed defective morphological maturation at P14, with the neurite length and branch number markedly reduced (Fig. $7 d-f$ ) and short dendritic processes that failed to reach layer I (Fig. 7c). These defects found in $\mathrm{K}_{\mathrm{ir}}$-expressing neurons indicated that reducing membrane depolarization was sufficient to impair morphological maturation of these developing cortical neurons.

\section{Discussion}

The results from the present study shed new light on the function of excitatory GABA during early cortical development in vivo. We

found that eliminating the excitatory action of GABA by premature KCC2 expression during perinatal development impaired the morphological maturation of cortical neurons, without affecting their radial migration to layer II/III of the somatosensory cortex. Electrophysiological recordings from cortical neurons in acute slices showed the presence of tonic excitation by endogenously secreted GABA and the conversion of tonic GABA action from excitation to inhibition by KCC2 transfection. Moreover, reducing neuronal excitability by overexpressing $\mathrm{K}_{\mathrm{ir}} 2.1$ in vivo partially mimicked the effect of premature KCC2 expression on morphological maturation. Together, these findings indicate that the depolarization caused by GABA signaling is essential for morphological maturation of neonatal cortical neurons in vivo.

Overexpression of $\mathrm{KCC} 2$ or $\mathrm{K}_{\mathrm{ir}}$ was accomplished by using in utero electroporation. This technique allowed us to overexpress proteins in developing cortical neurons for a substantial period during early development in vivo, with three notable features: first, we transfected the embryos only at E17-E18, leaving their earlier development unperturbed. Second, the transfection was targeted only to a small number of $\mathrm{VZ}$ progenitor cells that gave rise to a subpopulation of layer II/III cortical cells $(\sim 7 \%$ of the total number of neurons in the transfected area) (Fig. 3c), thus allowing examination of transfected neurons in their native environment. Third, because in utero electroporation of VZ cells eventually results in transfection of glutamatergic (pyramidal and spiny stellate) but not GABAergic cells (Hatanaka et al., 2004), we were examining the function of excitatory GABA on developing glutamatergic neurons, presumably without affecting endogenous GABA concentration in the cortex.

Excitatory GABAergic activities have been observed in various regions of the developing brain of many species ranging from reptiles to primates, suggesting that this is an evolutionarily conserved feature of the developing brain (Ben-Ari, 2002). However, despite many in vitro studies indicating trophic functions of GABA for regulating proliferation, migration, and morphological differentiation of developing neurons, there is very little in vivo evidence confirming these observations. Surprisingly, mice with deletion of genes coding for proteins responsible for GABA signaling showed no obvious defects in brain development. For example, mice with targeted deletion of genes coding for the GABA-synthesizing enzymes GADs (Asada et al., 1997; Kash et al., 1997) or for $\alpha_{1}$ or $\beta_{3}$ subunit of $\mathrm{GABA}_{\mathrm{A}}$ receptor (Homanics et al., 1997; Heinen et al., 2003) exhibited no gross abnormality in cortical morphology, despite the altered GABAergic transmission. The lack of in vivo GABA effects in mice may be attributed to compensatory mechanisms in knock-out mice or species-specific effects. Indeed, parallel in vitro studies on mouse and rat cortical 
cultures performed by the same group (Behar et al., 1999, 2000, 2001) suggested that glutamate rather than GABA is more important for migration of mouse but not rat cortical neurons. Our in vivo study on the rat brain permits a direct comparison with in vitro rat studies reported previously.

Although mice with gene knock-out in the GABA system did not show gross abnormality in the brain structure, detailed morphological examination of neurons had not been performed. Indeed, more recent studies have revealed subtle defects, such as a larger ventromedial nucleus and impaired dendritic spine in the visual cortex in $\alpha_{1}$ and $\beta_{3}$ knock-out mice (Dellovade et al., 2001; Heinen et al., 2003), respectively. Moreover, maturation of newborn granule cells was delayed in GAD65 knock-out mice (OverstreetWadiche et al., 2006). The unexpectedly mild phenotype found in the mutant mice of the GABAergic system may be attributable to developmental compensation with other transmitters (e.g., glycine, taurine, and glutamate) substituting GABA for the excitatory action (LoTurco et al., 1995; Flint et al., 1998). Such compensation may have been avoided by the present transfection method, which eliminated the early GABA excitation only during a limited perinatal period. Furthermore, potential compensatory actions through glycine and taurine would not be effective, because both of these amino acids activate $\mathrm{Cl}^{-}$ channels (Hussy et al., 1997), and their actions are likely to be affected by KCC2 expression in the same manner as GABAergic activity.

An in vivo role for excitatory GABA has been suggested in the hippocampus and dentate gyrus of adult rats, in which neurogenesis begins before birth and continues throughout the adult life (Ming and Song, 2005). Indeed, in vivo evidence has recently been obtained for a trophic function of GABA in the development of newly generated neurons in these regions of the adult brain in a manner similar to the development of neurons in the early developing brain, with the presence of excitatory GABA action before the glutamatergic input (Ming and Song, 2005; Overstreet et al., 2005; Song et al., 2005; Overstreet-Wadiche and Westbrook, 2006). These in vivo studies have shown that excitatory GABA is involved in neurogenesis, differentiation, morphological maturation, and synapse formation of adult newly generated hippocampal granule cells (Deisseroth et al., 2004; Tozuka et al., 2005; Ge et al., 2006). In particular, conversion of GABAergic excitation into inhibition by reducing the expression of $\mathrm{Na}^{+}-\mathrm{K}^{+}-\mathrm{Cl}^{-}$cotransporter NKCC1 impeded den-
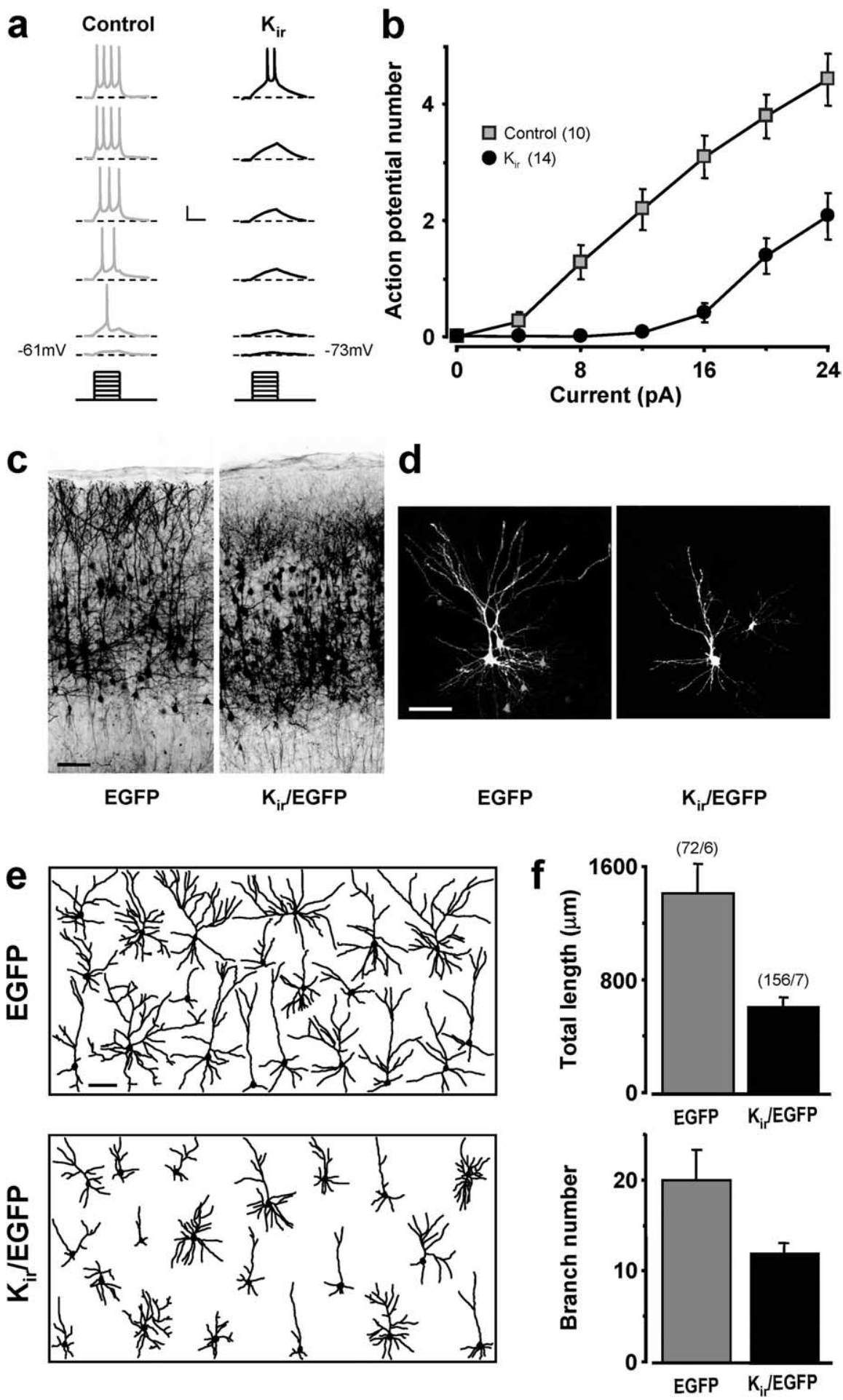

Figure 7. $\mathrm{K}_{\mathrm{ir}} 2.1$ overexpression reduced neuronal firing and impaired morphological maturation. $\boldsymbol{a}$, Example recordings showing membrane voltage responses to graded steps ( $4 \mathrm{pA}$ ) of current injections (bottom), for untransfected control cells (gray) and $\mathrm{K}_{\mathrm{ir}} /$ EGFP-expressing cells (black). Calibration: $200 \mathrm{~ms}, 20 \mathrm{mV}$. $\boldsymbol{b}$, Input- output curves for untransfected control cells and $\mathrm{K}_{\mathrm{ir}} / \mathrm{EGFP}$ expressing cells. Significant difference between the two groups of cells was found ( $p<0.0001$, one-way repeated-measures ANOVA; $p<0.05$, post hoc Holm-Sidak method). Recordings were performed at P8. Numbers in parentheses refer to the total number of cells recorded. $\mathbf{c}-\boldsymbol{f}$, Data from experiments similar to that in Figure 4, except that neurons were transfected with $\mathrm{K}_{\mathrm{ir}} /$ EGFP instead of KCC2/EGFP. $\boldsymbol{f}$, Both parameters were significantly different between the two groups ( $p<0.001$, KruskalWallis one-way ANOVA; $p<0.05$, post hoc Dunn's method).

dritic development of newly generated granule cells in the adult hippocampus (Ge et al., 2006). Our finding on the morphological effect of GABA excitation in the neonatal cortex is consistent with the latter finding in the adult hippocampus, 
although our perturbation of KCC2 expression resulted in more pronounced morphological effects. Thus, despite the dramatic differences in the environment of the developing cortex and adult hippocampus, GABA excitation appears to be critical for neuronal morphogenesis at all ages. The recent finding that KCC2 overexpression in ovo reduces innervation on choroid neurons in the peripheral chick nervous system (Liu et al., 2006) is also consistent with a defect in dendritic development.

Studies performed on a wide range of preparations suggest that GABAergic signaling is present and functional very early in the brain. In the germinative zones of the developing CNS, GABA acts as an autocrine/paracrine excitatory signal to either promote or inhibit cell proliferation, depending on the stage of differentiation of neural progenitors (LoTurco et al., 1995; Haydar et al., 2000; Liu et al., 2005). In the present study, we did not observe differences between the number of EGFP- or KCC2/EGFPexpressing neurons in proliferative zones or in the cortex. In particular, at E19, when almost all cells reside in the in VZ/SVZ (Fig. 2), the total number of transfected cells per section was $343 \pm 64$ for EGFP animals and $300 \pm 76$ for KCC2/EGFP embryos. Moreover, at P6, when almost all cells have arrived at CP (Fig. 2), the total number of transfected cells per section was $139 \pm 77$ for control EGFP animals and $193 \pm 48$ for KCC2/ EGFP embryos. Therefore, GABA excitation may not play an important role in regulating the proliferation of cortical progenitor cells. However, we note that, because of the variation in the amount of injected vectors in the ventricle, as well as in the placement of the electrode during electroporation, it was difficult to transfect the same number of cells consistently in each embryo. Hence, the present approach may not be optimal for detecting a difference in the proliferation of EGFP- and KCC2/EGFPexpressing cells.

GABA acts as an excitatory trophic signal to promote or inhibit migration of perinatal neurons in cultures of cortical slices or dissociated cells, depending on intrinsic cell properties and the cell's environment (Behar et al., 1996, 1998, 2000, 2001). However, in vivo studies using genetic models failed to confirm a role for excitatory GABA on neuronal migration. For example, in GAD65/67 double knock-out mice, which had only $0.02 \%$ of the normal GABA level in the cortex, no obvious defect in the size or layering pattern of the cortex was observed (Ji et al., 1999). In the present work, we showed directly that eliminating the excitatory action of GABA and of other transmitters activating $\mathrm{Cl}^{-}$conductances (e.g., glycine and taurine) did not affect the migration of a subpopulation of developing cortical neurons in vivo. Notably, we did not find any significant difference in the morphology of migrating cells transfected with EGFP or KCC2/EGFP at E21. Nevertheless, because we electroporated neural progenitors at E17-E18, a procedure that only resulted in overexpression in layer II/III pyramidal neurons of the somatosensory cortex, we cannot exclude potential effects of excitatory GABA on the migration of neurons born before or after E17-E18 (Hatanaka et al., 2004) or in different locations (e.g., ganglionic eminences) (Lopez-Bendito et al., 2006). Furthermore, because premature expression of KCC2 affects the $\mathrm{Cl}^{-}$gradient and therefore modifies only the activity of transmitters acting on $\mathrm{Cl}^{-}$-dependent conductances, we cannot rule out the possibility that GABA affects neuronal migration through metabotropic $\mathrm{GABA}_{\mathrm{B}}$ receptor signaling.

In addition to the phasic activation of $\mathrm{GABA}_{\mathrm{A}}$ receptors during synaptic transmission, recent studies have revealed the presence of tonic GABA actions characterized by a slow time course and prolonged activation of $\mathrm{GABA}_{\mathrm{A}}$ channels (Farrant and
Nusser, 2005). What are the sources of GABA that produce the tonic actions? Many types of developing neural progenitor cells produce and release GABA at various stages of differentiation (Verney, 2003). Immunohistochemical studies of rat embryos showed the presence of GABA-containing processes and cells well before the onset of synaptogenesis (Lauder et al., 1986; MarinPadilla, 1998). As more interneurons immigrate to the cortex, GABA-positive cells increase in number (Lavdas et al., 1999) and spread across the cortex by E16 (Lauder et al., 1986). Interestingly, developing neural tissues are enriched in GABA (BenitezDiaz et al., 2003), which could be supplied by circulation through an immature blood-brain barrier (Engelhardt, 2003) and an inefficient clearance of secreted GABA by immature uptake mechanisms (Demarque et al., 2002). Our results showing the abundance of cells and processes positive for GAD65/67 staining are consistent with the existing literature.

Persistent presence of endogenously secreted GABA may provide tonic excitatory drive for trophic functions before synapse formation (Owens and Kriegstein, 2002). Here, we showed that endogenous GABA in the developing cortex tonically depolarized developing cortical neurons by activating $\mathrm{GABA}_{\mathrm{A}}$ receptors. The tonic GABA-induced excitation may constitute a major depolarizing drive in the developing cortex when phasic excitatory activity is not operational and may be responsible for generating giant depolarizing potentials that propagate across developing neural tissues (Ben-Ari, 2002). The effect of GABA on the morphological maturation of cortical neurons appears to reside mainly in the depolarization that facilitates action potential firing, because neuronal morphological maturation was impaired by the overexpression of $\mathrm{K}_{\mathrm{ir}}$, which reduces the rate of firing as a result of a more negative resting membrane potential. Notably, the morphological impairment in $\mathrm{K}_{\mathrm{ir}}$-expressing cells was less substantial than in KCC2/EGFP-expressing neurons (Fig. $5 g$, 7f). We attribute this to the fact that KCC2 expression, by shifting the level of the $E_{\mathrm{Cl}}$ to a value lower than the resting potential of the cell, completely eliminated GABA-mediated excitation and converted the excitation to inhibition, whereas $\mathrm{K}_{\mathrm{ir}}$ expression only reduced the excitability of the cell by hyperpolarizing the membrane potential, thus merely reducing rather than eliminating GABAmediated excitation.

In this study, we showed that proper morphological maturation of cortical neurons during early development in vivo critically depends on the excitatory action of GABA. Because dendritic maturation is crucial for the establishment of synaptic contact and synapse maturation is also regulated by neuronal activity (Hartman et al., 2006; Shen et al., 2006), it would be of interest to determine whether excitatory GABA actions during early development also affect synapse maturation and circuit formation in vivo, in a manner similar to that found for newborn granule cells in adult hippocampus (Ge et al., 2006; Hartman et al., 2006). Such early excitatory GABA actions may have dramatic effects on the formation and function of neural circuits of the mature brain. Finally, our data suggest that drugs or insults that affect the action of excitatory GABA during early development are likely to have profound teratogenic consequences on the structural and functional development of the cerebral cortex, possibly leading to disorders such as fetal alcohol syndrome, autism, childhood schizophrenia, and other early-onset disorders relating to the GABAergic system.

\section{References}

Asada H, Kawamura Y, Maruyama K, Kume H, Ding RG, Kanbara N, Kuzume H, Sanbo M, Yagi T, Obata K (1997) Cleft palate and decreased 
brain gamma-aminobutyric acid in mice lacking the $67-\mathrm{kDa}$ isoform of glutamic acid decarboxylase. Proc Natl Acad Sci USA 94:6496-6499.

Barbin G, Pollard H, Gaiarsa JL, Ben Ari Y (1993) Involvement of GABAA receptors in the outgrowth of cultured hippocampal neurons. Neurosci Lett 152:150-154.

Behar TN, Li YX, Tran HT, Ma W, Dunlap V, Scott C, Barker JL (1996) GABA stimulates chemotaxis and chemokinesis of embryonic cortical neurons via calcium-dependent mechanisms. J Neurosci 16:1808-1818.

Behar TN, Schaffner AE, Scott CA, O'Connell C, Barker JL (1998) Differential response of cortical plate and ventricular zone cells to GABA as a migration stimulus. J Neurosci 18:6378-6387.

Behar TN, Scott CA, Greene CL, Wen X, Smith SV, Maric D, Liu QY, Colton CA, Barker JL (1999) Glutamate acting at NMDA receptors stimulates embryonic cortical neuronal migration. J Neurosci 19:4449-4461.

Behar TN, Schaffner AE, Scott CA, Greene CL, Barker JL (2000) GABA receptor antagonists modulate postmitotic cell migration in slice cultures of embryonic rat cortex. Cereb Cortex 10:899-909.

Behar TN, Smith SV, Kennedy RT, McKenzie JM, Maric I, Barker JL (2001) $\mathrm{GABA}(\mathrm{B})$ receptors mediate motility signals for migrating embryonic cortical cells. Cereb Cortex 11:744-753.

Ben-Ari Y (2002) Excitatory actions of GABA during development: the nature of the nurture. Nat Rev Neurosci 3:728 -739.

Benitez-Diaz P, Miranda-Contreras L, Mendoza-Briceno RV, PenaContreras Z, Palacios-Pru E (2003) Prenatal and postnatal contents of amino acid neurotransmitters in mouse parietal cortex. Dev Neurosci 25:366-374.

Borodinsky LN, O’Leary D, Neale JH, Vicini S, Coso OA, Fiszman ML (2003) GABA-induced neurite outgrowth of cerebellar granule cells is mediated by $\mathrm{GABA}(\mathrm{A})$ receptor activation, calcium influx and CaMKII and erk $1 / 2$ pathways. J Neurochem 84:1411-1420.

Clayton GH, Owens GC, Wolff JS, Smith RL (1998) Ontogeny of cation-Clcotransporter expression in rat neocortex. Brain Res Dev Brain Res 109:281-292.

DeFazio RA, Keros S, Quick MW, Hablitz JJ (2000) Potassium-coupled chloride cotransport controls intracellular chloride in rat neocortical pyramidal neurons. J Neurosci 20:8069-8076.

Deisseroth K, Singla S, Toda H, Monje M, Palmer TD, Malenka RC (2004) Excitation-neurogenesis coupling in adult neural stem/progenitor cells. Neuron 42:535-552.

Dellovade TL, Davis AM, Ferguson C, Sieghart W, Homanics GE, Tobet SA (2001) GABA influences the development of the ventromedial nucleus of the hypothalamus. J Neurobiol 49:264-276.

Demarque M, Represa A, Becq H, Khalilov I, Ben Ari Y, Aniksztejn L (2002) Paracrine intercellular communication by a Ca2+- and SNAREindependent release of GABA and glutamate prior to synapse formation. Neuron 36:1051-1061.

Engelhardt B (2003) Development of the blood-brain barrier. Cell Tissue Res 314:119-129.

Farrant M, Nusser Z (2005) Variations on an inhibitory theme: phasic and tonic activation of GABA(A) receptors. Nat Rev Neurosci 6:215-229.

Fiumelli H, Cancedda L, Poo MM (2005) Modulation of GABAergic transmission by activity via postsynaptic Ca2 +-dependent regulation of KCC2 function. Neuron 48:773-786.

Flint AC, Liu X, Kriegstein AR (1998) Nonsynaptic glycine receptor activation during early neocortical development. Neuron 20:43-53.

Ge S, Goh EL, Sailor KA, Kitabatake Y, Ming GL, Song H (2006) GABA regulates synaptic integration of newly generated neurons in the adult brain. Nature 439:589-593.

Hartman KN, Pal SK, Burrone J, Murthy VN (2006) Activity-dependent regulation of inhibitory synaptic transmission in hippocampal neurons. Nat Neurosci 9:642-649.

Hatanaka Y, Hisanaga S, Heizmann CW, Murakami F (2004) Distinct migratory behavior of early- and late-born neurons derived from the cortical ventricular zone. J Comp Neurol 479:1-14.

Haydar TF, Wang F, Schwartz ML, Rakic P (2000) Differential modulation of proliferation in the neocortical ventricular and subventricular zones. J Neurosci 20:5764-5774.

Heinen K, Baker RE, Spijker S, Rosahl T, van Pelt J, Brussaard AB (2003) Impaired dendritic spine maturation in GABAA receptor alpha1 subunit knock out mice. Neuroscience 122:699-705.

Homanics GE, Delorey TM, Firestone LL, Quinlan JJ, Handforth A, Harrison NL, Krasowski MD, Rick CE, Korpi ER, Makela R, Brilliant MH, Hagi- wara N, Ferguson C, Snyder K, Olsen RW (1997) Mice devoid of gamma-aminobutyrate type A receptor beta3 subunit have epilepsy, cleft palate, and hypersensitive behavior. Proc Natl Acad Sci USA 94:4143-4148.

Hussy N, Deleuze C, Pantaloni A, Desarmenien MG, Moos F (1997) Agonist action of taurine on glycine receptors in rat supraoptic magnocellular neurones: possible role in osmoregulation. J Physiol 502:609-621.

Ji F, Kanbara N, Obata K (1999) GABA and histogenesis in fetal and neonatal mouse brain lacking both the isoforms of glutamic acid decarboxylase. Neurosci Res 33:187-194.

Kash SF, Johnson RS, Tecott LH, Noebels JL, Mayfield RD, Hanahan D, Baekkeskov S (1997) Epilepsy in mice deficient in the $65-\mathrm{kDa}$ isoform of glutamic acid decarboxylase. Proc Natl Acad Sci USA 94:14060-14065.

Kriegstein AR (2005) Constructing circuits: neurogenesis and migration in the developing neocortex. Epilepsia 46 [Suppl 7]:15-21.

Kyrozis A, Reichling DB (1995) Perforated-patch recording with gramicidin avoids artifactual changes in intracellular chloride concentration. J Neurosci Methods 57:27-35.

Lauder JM, Han VK, Henderson P, Verdoorn T, Towle AC (1986) Prenatal ontogeny of the GABAergic system in the rat brain: an immunocytochemical study. Neuroscience 19:465-493.

Lavdas AA, Grigoriou M, Pachnis V, Parnavelas JG (1999) The medial ganglionic eminence gives rise to a population of early neurons in the developing cerebral cortex. J Neurosci 19:7881-7888.

Liu X, Wang Q, Haydar TF, Bordey A (2005) Nonsynaptic GABA signaling in postnatal subventricular zone controls proliferation of GFAPexpressing progenitors. Nat Neurosci 8:1179-1187.

Liu Z, Neff RA, Berg DK (2006) Sequential interplay of nicotinic and GABAergic signaling guides neuronal development. Science 314:1610-1613.

Lopez-Bendito G, Cautinat A, Sanchez JA, Bielle F, Flames N, Garratt AN, Talmage DA, Role LW, Charnay P, Marin O, Garel S (2006) Tangential neuronal migration controls axon guidance: a role for neuregulin-1 in thalamocortical axon navigation. Cell 125:127-142.

LoTurco JJ, Owens DF, Heath MJ, Davis MB, Kriegstein AR (1995) GABA and glutamate depolarize cortical progenitor cells and inhibit DNA synthesis. Neuron 15:1287-1298.

Maric D, Liu QY, Maric I, Chaudry S, Chang YH, Smith SV, Sieghart W, Fritschy JM, Barker JL (2001) GABA expression dominates neuronal lineage progression in the embryonic rat neocortex and facilitates neurite outgrowth via $\mathrm{GABA}_{\mathrm{A}}$ autoreceptor $/ \mathrm{Cl}^{-}$channels. J Neurosci 21:2343-2360.

Marin-Padilla M (1998) Cajal-Retzius cells and the development of the neocortex. Trends Neurosci 21:64-71.

Marty S, Berninger B, Carroll P, Thoenen H (1996) GABAergic stimulation regulates the phenotype of hippocampal interneurons through the regulation of brain-derived neurotrophic factor. Neuron 16:565-570.

Meijering E, Jacob M, Sarria JC, Steiner P, Hirling H, Unser M (2004) Design and validation of a tool for neurite tracing and analysis in fluorescence microscopy images. Cytometry A 58:167-176.

Ming GL, Song H (2005) Adult neurogenesis in the mammalian central nervous system. Annu Rev Neurosci 28:223-250.

Overstreet WL, Bromberg DA, Bensen AL, Westbrook GL (2005) GABAergic signaling to newborn neurons in dentate gyrus. J Neurophysiol 94:4528-4532.

Overstreet-Wadiche LS, Westbrook GL (2006) Functional maturation of adult-generated granule cells. Hippocampus 16:208-215.

Overstreet-Wadiche LS, Bensen AL, Westbrook GL (2006) Delayed development of adult-generated granule cells in dentate gyrus. J Neurosci 26:2326-2334.

Owens DF, Kriegstein AR (2002) Is there more to GABA than synaptic inhibition? Nat Rev Neurosci 3:715-727.

Owens DF, Boyce LH, Davis MB, Kriegstein AR (1996) Excitatory GABA responses in embryonic and neonatal cortical slices demonstrated by gramicidin perforated-patch recordings and calcium imaging. J Neurosci 16:6414-6423.

Represa A, Ben-Ari Y (2005) Trophic actions of GABA on neuronal development. Trends Neurosci 28:278-283.

Reynolds A, Mercado A, Mount DB, Drapeau P (2004) Expression of the 
potassium-chloride co-transporter 2 in zebrafish embryos. Soc Neurosci Abstr 30:401.13.

Rivera C, Voipio J, Payne JA, Ruusuvuori E, Lahtinen H, Lamsa K, Pirvola U, Saarma M, Kaila K (1999) The K+/Cl- co-transporter KCC2 renders GABA hyperpolarizing during neuronal maturation. Nature 397:251-255.

Saito T, Nakatsuji N (2001) Efficient gene transfer into the embryonic mouse brain using in vivo electroporation. Dev Biol 240:237-246.

Shen W, Wu B, Zhang Z, Dou Y, Rao ZR, Chen YR, Duan S (2006) Activityinduced rapid synaptic maturation mediated by presynaptic cdc42 signaling. Neuron 50:401-414.

Song H, Kempermann G, Overstreet WL, Zhao C, Schinder AF, Bischofberger
J (2005) New neurons in the adult mammalian brain: synaptogenesis and functional integration. J Neurosci 25:10366-10368.

Tapia JC, Mentis GZ, Navarrete R, Nualart F, Figueroa E, Sanchez A, Aguayo LG (2001) Early expression of glycine and GABA(A) receptors in developing spinal cord neurons. Effects on neurite outgrowth. Neuroscience 108:493-506.

Tozuka Y, Fukuda S, Namba T, Seki T, Hisatsune T (2005) GABAergic excitation promotes neuronal differentiation in adult hippocampal progenitor cells. Neuron 47:803-815.

Verney C (2003) Phenotypic expression of monoamines and GABA in the early development of human telencephalon, transient or not transient. J Chem Neuroanat 26:283-292. 